\title{
Comparison of pulmonary artery and pulmonary venous wedge pressure in congenital heart disease
}

\author{
Richard E. Hawker ${ }^{1}$ and John M. Celermajer \\ From The Adolph Basser Institute of Cardiology, Royal Alexandra Hospital for Children, \\ Sydney, Australia
}

A statistical comparison of pulmonary artery and pulmonary vein wedge pressures has been made by the correlation coefficient method, in patients with congenital heart disease.

The correlation was poor $(r=0.66)$ in patients with a pulmonary artery mean pressure in the normal range, but good $(r=0.86)$ in patients with mild to moderate pulmonary hypertension.

An analysis of patients in whom catheterization of the pulmonary artery may not always be possible, showed a good correlation in transposition of the great arteries $(r=0.84)$ and ventricular septal defect, with banding of the main pulmonary artery $(r=0.93)$, but not as good in tetralogy of Fallot and pulmonary stenosis.

Despite the poor statistical correlation in the overall group, it was found that patients with pulmonary vein wedge mean pressure below the upper limits of normal had a pulmonary artery mean pressure below this level in 81 of 87 cases and minimally raised pulmonary artery mean pressure in the remaining 6. Likewise, a raised pulmonary artery pressure was found in 33 out of 34 cases with high pulmonary vein wedge mean pressure.

Therefore it is concluded that (I) if the pulmonary artery is not entered, a pulmonary vein wedge pressure within the normal range makes it very unlikely that the pulmonary artery pressure is raised; (2) if the pulmonary vein wedge pressure is raised, the pulmonary artery pressure is almost certainly raised. However, this rise cannot be quantitated from the pulmonary vein wedge trace; and (3) the pulmonary vein wedge mean pressure is a useful indication of pulmonary artery mean pressure in selected cases of congenital heart disease.

The pulmonary vein wedge pressure is sometimes used as an indirect measurement of pulmonary artery pressure in cases of congenital heart disease when catheterization of the pulmonary artery is unsuccessful. A recent publication (Rao and Sissman, 197I) examined the relation of pulmonary venous wedge to pulmonary arterial pressures. However, a statistical correlation of pulmonary vein wedge and pulmonary artery pressures in congenital heart disease has not to our knowledge been published, though it is known that the correlation is poor in the presence of pulmonary hypertension (Zimmerman, 1966). It is the purpose of this paper to present a statistical correlation between mean pulmonary vein wedge and mean pulmonary artery pressures obtained at routine and emergency cardiac catheterization of infants and children with congenital heart disease, and to assess the usefulness of pulmonary vein wedge pressure records. The mean rather than

Received 7 July 1972.

1 Present address: The Johns Hopkins Hospital, Baltimore, Maryland, U.S.A. the systolic or diastolic pressure was selected for statistical analysis as it was thought that the correlation of mean pressures would be more meaningful because it might be less affected by the damping effect on the pressure wave transmitted through the pulmonary vascular bed. Moreover, the mean pulmonary arterial pressure is used in the calculations of pulmonary vascular resistance and resistance ratios, and so in the assessment of pulmonary vascular disease.

\section{Subjects and methods}

The reports of cardiac catheterizations performed between February 1968 and September 1970 in the Cardiac Department of the Royal Alexandra Hospital for Children were reviewed. In 187 of these, a pulmonary vein wedge pressure was recorded and in 135 both pulmonary artery and pulmonary vein wedge pressures were available. The pulmonary vein wedge pressure recording was considered adequate only if there was a recognizable arterial type wave form present and if there was the expected wave form change on withdrawal of the catheter from the wedge position to the 
pulmonary vein in cases where a withdrawal trace was recorded. Cases known to have peripheral pulmonary artery stenosis were excluded since it could not be determined if pulmonary artery pressures had been recorded beyond the obstruction. The pressure traces of all cases in which there was a greater than 20 per cent discrepancy between pulmonary artery and pulmonary vein wedge pressures were reviewed and 13 cases were rejected on the basis of incomplete information or technically inadequate pulmonary vein wedge traces.

The ages of the patients ranged from 18 hours to 13 years. Neonates were curarized, intubated, and ventilated during the procedure, while infants and older children were studied under local anaesthesia with premedication of omnopon and scopolamine except for those weighing less than $6 \mathrm{~kg}$ who were given morphine.

A 5 or 6 French gauge endhole catheter ${ }^{1}$ was used to record both pulmonary artery and pulmonary vein wedge pressure. The catheters were connected via Statham 23 De pressure transducers to a Sanborn 8-channel photographic recorder. The reference level for zero pressure was at the midchest position.

Comparison was made between the pulmonary artery and pulmonary vein wedge mean pressures except in cases with banding of the main pulmonary artery in which right or left pulmonary artery mean pressure and the pulmonary vein wedge mean pressure from the corresponding side was used. The paired results were considered as follows.

Group $A: 82$ cases with mean pulmonary artery pressure below and in the normal range of Kjellberg et al. (I955) (i.e. 8 to $19 \mathrm{mmHg}$ ).

Group $B$ : I9 cases with mean pulmonary artery pressure between 20 and $39 \mathrm{mmHg}$.

Group $C: 2$ cases with mean pulmonary artery pressure above $39 \mathrm{mmHg}$.

1 U.S.C.I. Lehman.

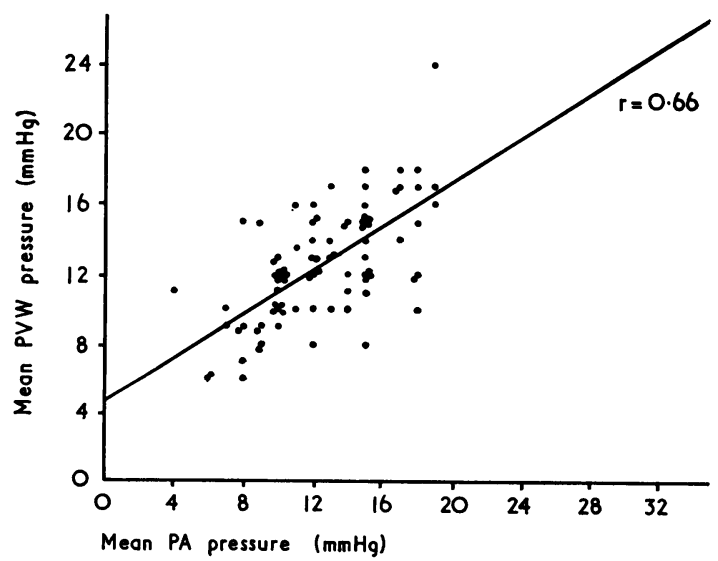

FIG. I Statistical comparison of mean pulmonary artery and pulmonary vein wedge pressures: Group $A$ (mean pulmonary artery pressure less than $20 \mathrm{mmHg}$ ).
Comparisons were also made of the pulmonary artery and pulmonary vein wedge mean pressure in (I) transposition of the great arteries, (2) pulmonary stenosis and tetralogy of Fallot, and (3) ventricular septal defect, with banding of the main pulmonary artery, because in these conditions the pulmonary artery may be difficult to catheterize. Eleven additional patients with these malformations were added to the number drawn from the original series to increase the significance of the results. Statistical comparison of paired observations was made by using the regression equation and correlation coefficient method.

Finally, cases in which the pulmonary artery was not entered were examined to see if any significance could be placed on the recorded pulmonary vein wedge pressures.

\section{Results}

Group A: normal and subnormal mean pulmonary artery pressures (Fig. I)

There was a poor correlation in this group (correlation coefficient $r=0.66$, standard error of the estimate $(\mathrm{SE}$ est. $)=2.49$, slope $=0.63)$.

However, in only one case was the pulmonary vein wedge mean pressure greater than $20 \mathrm{mmHg}$. The greatest discrepancy between mean pulmonary artery and pulmonary vein wedge was $8 \mathrm{mmHg}$. The slope of the line being less than I indicates the overall tendency for the pulmonary artery pressure to be higher than the pulmonary vein wedge pressure.

\section{Group B: mean pressure 20 to $39 \mathrm{mmHg}$ (Fig. 2)}

The correlation was good in this group $(r=0.86$, SE est. $=2.53$ ). The range of pulmonary vein wedge

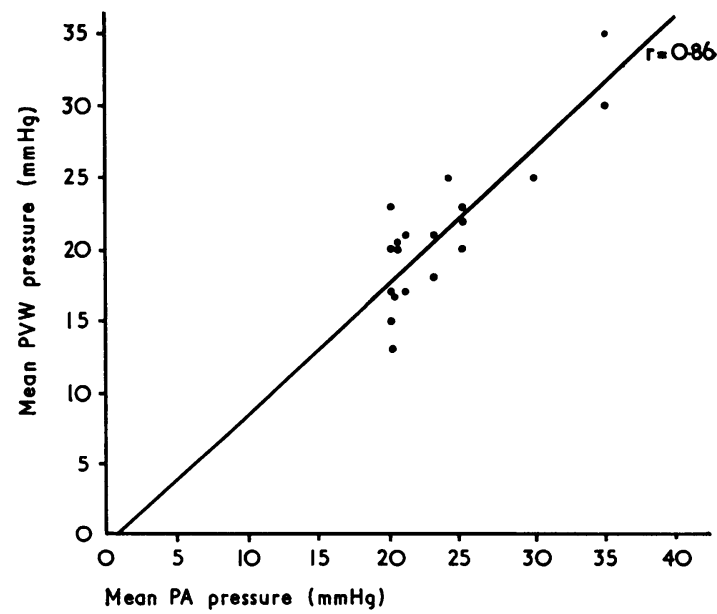

FIG. 2 Statistical comparison of mean pulmonary artery and pulmonary vein wedge pressures: Group $B$ (mean pulmonary artery pressure 20-39 $\mathrm{mmHg}$ ). 
pressure was 13 to $35 \mathrm{mmHg}$, and the greatest discrepancy between pulmonary artery and pulmonary vein wedge was $7 \mathrm{mmHg}$.

\section{Group C: mean pulmonary artery pressures greater than $39 \mathrm{mmHg}$ (Fig. 3)}

This group showed a very poor correlation $(r=0.134$, SE est. $=7.78)$. However, in all cases the mean pulmonary vein wedge pressure was $20 \mathrm{mmHg}$ or greater. The slope of the regression line is negative, indicating that in this range the mean pulmonary vein wedge pressure actually becomes less the higher the mean pulmonary artery pressure rises. No mean pulmonary vein wedge pressure higher than $50 \mathrm{mmHg}$ was recorded.

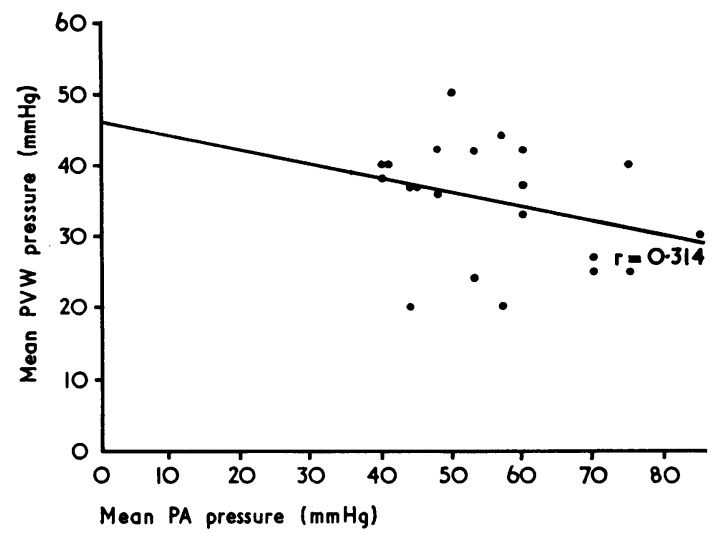

FIG. 3 Statistical comparison of mean pulmonary artery and pulmonary vein wedge pressures: Group $C$ (mean pulmonary artery pressure greater than 39 $\mathrm{mmHg})$.

The tendency for the discrepancy between mean pulmonary artery and mean pulmonary vein wedge pressures to become greater with increasing pulmonary artery pressure is shown in Fig. 4.

Transposition of the great arteries -27 cases (Fig. 5)

A good correlation was obtained but there was a considerable scatter at the higher pulmonary artery pressures $(r=0.84$, SE est. $=6 \cdot 42)$.

Tetralogy of Fallot and pulmonary valve stenosis -29 cases (Fig. 6)

The correlation was poorer for this group $(r=0.7$, SE est. $=2.66$, slope $=0.608$ ). However, the greatest discrepancy was only $7 \mathrm{mmHg}$.

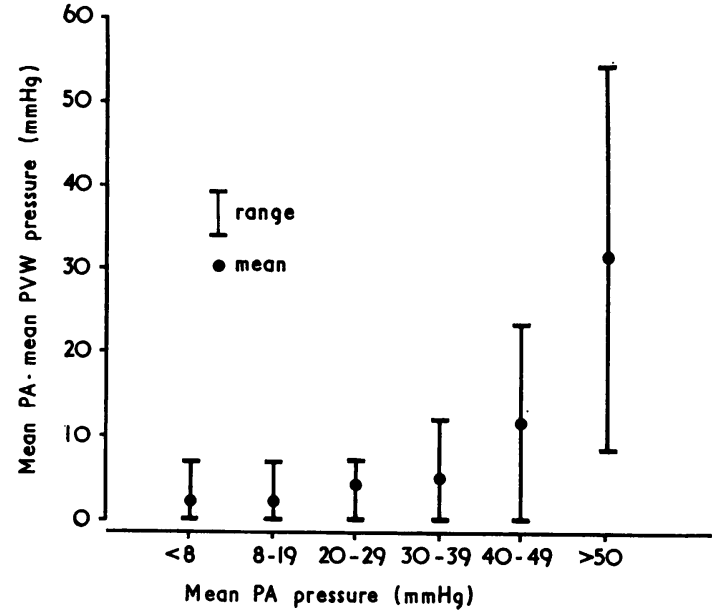

FIG. 4 Statistical comparison of mean pulmonary artery and pulmonary vein wedge pressures: the discrepancy between mean pulmonary artery and pulmonary vein wedge pressures increases with increasing pulmonary artery pressure.

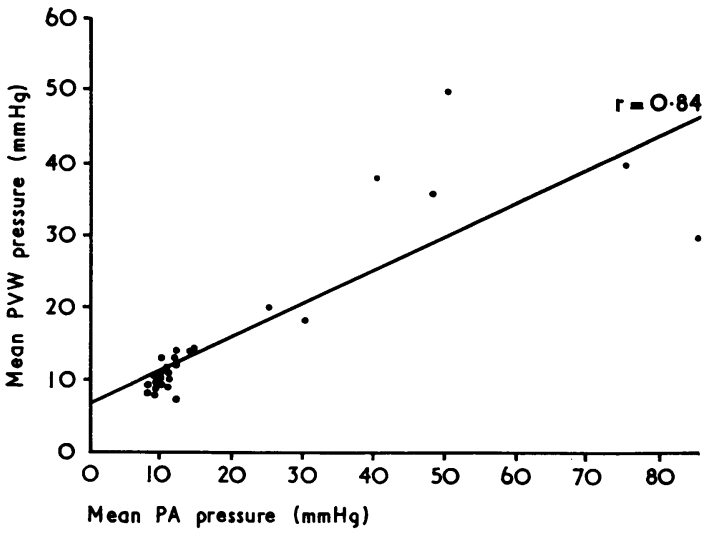

FIG. 5 Statistical comparison of mean pulmonary artery and pulmonary vein wedge pressures: transposition of the great arteries.

Ventricular septal defect with banded pulmonary artery -6 cases (Fig. 7)

A good correlation was obtained for this small group $(r=0.93$, slope $=I \cdot I 6$, SE est. $=I \cdot 79)$. The slope of the regression line is greater than $\mathrm{I}$, indicating the tendency for the pulmonary vein wedge pressure to be higher than the pulmonary artery pressures. 


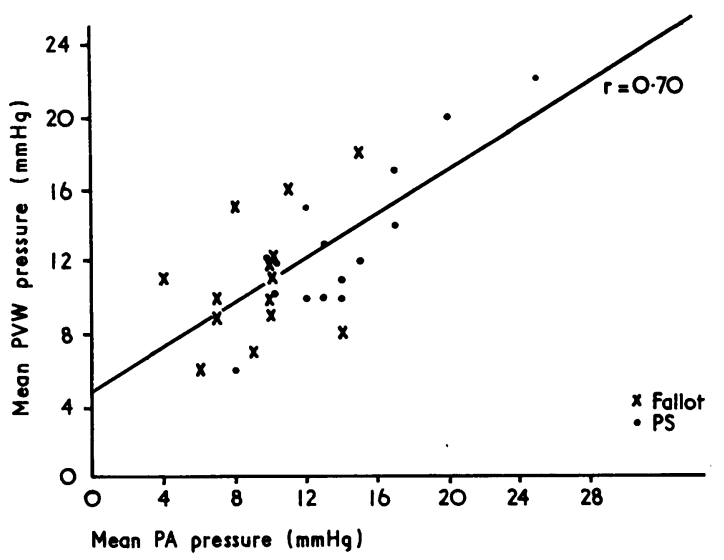

FIG. 6 Statistical comparison of mean pulmonary artery and pulmonary vein wedge pressures: tetralogy of Fallot and pulmonary stenosis.

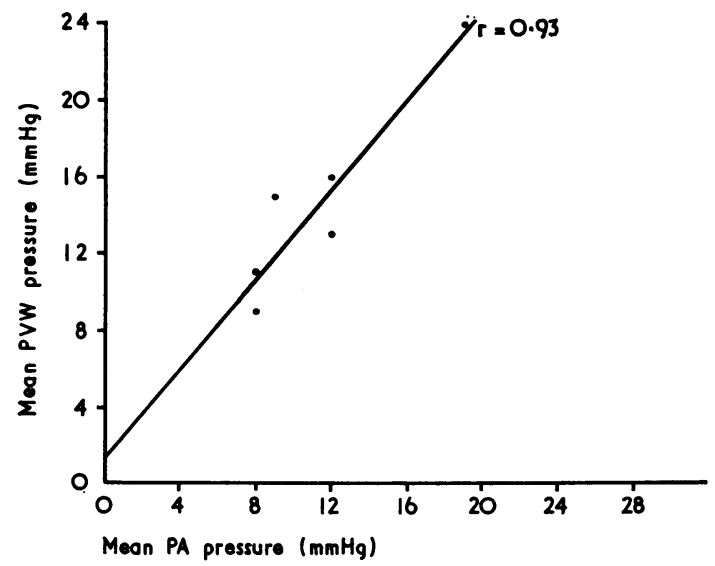

FIG. 7 Statistical comparison of mean pulmonary artery and pulmonary vein wedge pressures: ventricular septal defect with banding of main pulmonary artery.

\section{Prediction of pulmonary artery pressure from} pulmonary vein wedge pressure

The ability to predict from the pulmonary vein wedge pressure record whether the pulmonary artery pressure is raised or normal is shown in Tables $I$ and 2. It is seen that 8I out of 87 patients without a raised pulmonary vein wedge mean pressure did not have raised pulmonary artery mean pressure and no patient in this group had a pulmonary artery mean pressure greater than $23 \mathrm{mmHg}$. On the other hand, raised mean pulmonary vein wedge pressure was associated with a raised pulmonary artery pressure in 33 out of 34 cases.
TABLE I Mean pulmonary artery pressure in cases with pulmonary vein wedge mean pressure. $\leq 19 \mathrm{mmHg}$

\begin{tabular}{lc}
\hline $\begin{array}{l}\text { Pulmonary artery } \\
\text { pressure }(\mathrm{mmHg})\end{array}$ & No. of cases \\
\hline 19 & $8 \mathrm{I}$ \\
$20-21$ & 5 \\
$22-23$ & 1 \\
$>23$ & 0 \\
\hline Total & 87 \\
\hline
\end{tabular}

TABLE 2 Mean pulmonary artery pressure in cases with pulmonary vein wedge pressure. $>19 \mathrm{mmHg}$

\begin{tabular}{ll}
\hline $\begin{array}{l}\text { Pulmonary artery } \\
\text { pressure }\end{array}$ & No. of cases \\
\hline Normal & I \\
Raised & 33 \\
\hline Total & 34 \\
\hline
\end{tabular}

Pulmonary vein pressure when pulmonary artery not entered

Table 3 shows a group of 14 patients with raised mean pulmonary vein wedge in whom the pulmonary artery was not entered. In the 9 cases with transposition of the great arteries, the pressure was recorded before balloon septostomy. The case with pulmonary valve fusion aged I week is, therefore, the only case out of 14 in which raised pulmonary artery pressure would not be anticipated.

TABLE 3 Cases with pulmonary vein wedge mean pressure. $>19 \mathrm{mmHg}$ in which pulmonary artery not entered

\begin{tabular}{ll}
\hline Diagnosis & $\begin{array}{l}\text { No. of } \\
\text { cases }\end{array}$ \\
\hline Neonates & $\left\{\begin{array}{l}\text { Transposition of great arteries } \\
\text { Pulmonary atresia with intact inter- } \\
\text { ventricular septum, persistent } \\
\text { ductus arteriosus } \\
\text { Truncus arteriosus }\end{array}\right.$ \\
Older children $\left\{\begin{array}{l}\text { Complicated transposition of } \\
\text { great arteries (I year) } \\
\text { Tetralogy of Fallot with right } \\
\text { Blalock's anastomosis }\end{array}\right.$ & I \\
\hline Total & I \\
\hline
\end{tabular}

* Mild concentric hypertrophy of pulmonary arterioles found at necropsy. 
Table 4 shows that at least 25 out of the 29 cases with normal pulmonary vein wedge might have been expected to have a normal pulmonary artery pressure.

TABLE 4 Cases with pulmonary vein wedge mean pressure. $\leq 19 \mathrm{mmHg}$ in which pulmonary artery not entered

\begin{tabular}{ll}
\hline Diagnosis & $\begin{array}{l}\text { No. of } \\
\text { cases }\end{array}$ \\
\hline Transposition of great arteries + ventricular septal & \\
$\quad$ defect + pulmonary stenosis & 8 \\
Tetralogy of Fallot & 7 \\
Transposition of great arteries + persistent ductus & 3 \\
$\quad$ arteriosus (neonates) & 4 \\
Pulmonary valve stenosis & 3 \\
Pulmonary atresia & 3 \\
Tricuspid atresia & I \\
Transposition of great arteries + ventricular septal & 29 \\
\hline defect + persistent ductus arteriosus (I year) & \\
\hline Total & \\
\hline
\end{tabular}

* Includes cases with either single ventricle or ventricular septal defect, and either pulmonary stenosis or atresia.

\section{Discussion}

The value of the pulmonary vein wedge pressure recording is related to its ability to predict the pulmonary artery pressure at cardiac catheterization. In 1952, Weissel, Salzmann, and Vetter had observed the arterial form of the pulmonary vein wedge pressure wave, but could not relate its pressure or contour to that in the pulmonary arteries. Wilson, Hoseth, and Dempsey (1955) recognized that the wedging phenomena depended on the lack of anastomosis between pulmonary arterioles and the large veins, the absence of valves in the veins, and the rich capillary network in the lungs. By occluding flow, the catheter becomes an extension of a column of blood which transmits pressure from the opposite side of the lung bed. Wilson produced an excellent correlation of simultaneously recorded pulmonary artery and pulmonary vein wedge pressure in patients undergoing thoracotomy for lung disease or for mitral valvotomy (Wilson et al., 1955) and in open chest normal dogs (Wilson et al., 1953), while Connolly and Wood (1955) could not obtain good correlation at catheterization in 9 patients with atrial septal defect and partial anomalous pulmonary venous return. However, Gensini, Balchum, and Blount (1955) obtained good correlation in 5 similar patients, and Kjellberg et al. (1955) stated that his group obtained a good correlation in a large series of patients without pulmonary hypertension but did not record their results. Most recently, Rao and Sissman (I97I) have compared pulmonary venous wedge to pulmonary arterial pressures in 60 children. Though their figures were not subjected to statistical analysis the results and conclusions were almost identical with those of the present study.

Despite these conflicting reports we had expected to find better statistical correlation than we did, at least in the normal range of pressures. The simplest explanation for the discrepancy between the pulmonary artery and pulmonary vein wedge pressure in the normal range is the lack of contemporaneous readings, for the minute-to-minute changes in haemodynamics under the conditions of catheterization were probably considerable. Reflex pulmonary arterial constriction in response to pulmonary vein distension has been well established ( $\mathrm{Hy}-$ man and Sanchez, 1964; Lloyd and Schneider, 1969), but it seems unlikely that wedging of a 5 or 6 French gauge catheter would distend a pulmonary vein sufficiently to trigger these reflexes and produce an artefactually low pulmonary vein wedge pressure. Gensini et al. (1955) had noted that the pulmonary vein wedge pressure exceeded the pulmonary artery pressure in their case of pulmonary stenosis and concluded that the catheter had significantly decreased the area of the narrowed pulmonary valve. Therefore, the inclusion of these cases and those with tetralogy of Fallot and pulmonary stenosis which showed this phenomenon may also have impaired the correlation in Group I.

Gensini considered that increasing pulmonary vascular resistance did not invalidate the pulmonary artery - pulmonary vein wedge relations, but admitted that he had no case with very high resistance. Connolly and Wood (1955), however, recognized a worsening of the correlation of mean pressure and wave form with increasing pulmonary vascular resistance and felt that the structural changes in the pulmonary arteries, which tend to decrease flow, interfere with the correlation. The good correlation in Group B in this series suggests a satisfactory transmission of pressure waves at this level of pulmonary artery pressure. The statistical correlation in Group B is better than in Group A, simply because of the higher numerical value of the pressure samples without the discrepancy between pulmonary artery and pulmonary vein wedge pressures being greater (see Fig 4). The results in Group C certainly support Connolly's findings. It is possible that there is a critical arteriolar diameter below which pressure wave transmission becomes distorted. This distortion probably results from changes in the sites of reflection of the primary pressure wave. Unlike the situation in the systemic circulation where reflection 
occurs from a single site at arteriolar level (O'Rourke, I967), reflection occurs at several different sites in the normal pulmonary circulation (Braun and Stern, 1967; Wiener et al., 1966). The concept of a critical pulmonary artery pressure beyond which pressure transmission is poor is supported by one of our patients with ventricular septal defect and pulmonary hypertension. While breathing room air the mean pulmonary artery pressure was $60 \mathrm{mmHg}$ and the pulmonary vein wedge pressure $42 \mathrm{mmHg}$. On breathing approximately $60 \mathrm{per}$ cent oxygen the mean pulmonary artery pressure fell to $48 \mathrm{mmHg}$ while the pulmonary vein wedge pressure remained unchanged.

In the present study systolic and diastolic levels in the pulmonary venous wedge pressure wave were measured but not subjected to detailed analysis for reasons mentioned above. In general, however, the results for the systolic and diastolic pressures paralleled those for mean pressure as they did also in the study by Rao and Sissman (1971).

Despite the statistically poor correlation between pulmonary artery and pulmonary vein wedge pressure demonstrated here, two useful facts emerge from this study.

I) A raised pulmonary vein wedge pressure is a reliable indication of a raised pulmonary arterial pressure (Table 2) and this may be vital information in patients where pulmonary artery catheterization has proved impossible.

2) The demonstration of a normal pulmonary vein wedge pressure is a reliable indication that the pulmonary artery pressure is normal or, at most, mildly raised.

Nevertheless, the pulmonary vein wedge pressure should not be relied upon if entry to the pulmonary artery is possible by special techniques, e.g. via a systemic to pulmonary artery shunt or by use of the floppy wire (Celermajer, Venables, and Bowdler, 1970) or other techniques (Carr and Wells, 1966; Rahimtoola, Ongley, and Swan, 1966).

Thus, provided the limitation of the measurement is clearly recognized, the pulmonary vein wedge pressure recording can prove a valuable aid to the haemodynamic assessment of some cases of congenital heart disease.

\section{References}

Braun, K., and Stern, S. (1967). Functional significance of the pulmonary venous system. American fournal of Cardiology, 20, 56.

Carr, I., and Wells, B. (1966). Coaxial flow-guided catheterization of the pulmonary artery in transposition of the great arteries. Lancet, 2, 318.

Celermajer, J. M., Venables, A. W., and Bowdler, J. D. (1970). Catheterization of the pulmonary artery in transposition of the great arteries. A simple method. Circulation, 4r, I053.

Connolly, D. C., and Wood, E. H. (1955). The pulmonary vein wedge pressure in man. Circulation Research, 3, 7.

Gensini, G., Balchum, O. J., and Blount, S. G., Jr. (I955). The transmission of the pulmonary artery pressure across the capillary bed of the lungs. American Heart fournal, 49, 507.

Hyman, A. L., and Sanchez, G. (1964). Alterations in pulmonary vasculature and urine produced by acute distension of a single pulmonary vein in intact dogs (abstract). Circulation, 30, Suppl. III, 98.

Kjellberg, S. R., Mannheimer, E., Rudhe, U., and Jonsson, B. (1955). Diagnosis of Congenital Heart Disease. Year Book Publisher, Chicago.

Lloyd, T. C., and Schneider, A. J. L. (I969). Relation of pulmonary arterial pressure to pressure in the pulmonary venous system. Fournal of Applied Physiology, 27, 489.

O'Rourke, M. F. (1967). Pressure and flow waves in systemic arteries and the anatomical design of the arterial system. Fournal of Applied Physiology, 23, 139.

Rahimtoola, S. H., Ongley, P. A., and Swan, H. J. C. (I966). Percutaneous suprasternal puncture (Radner technique) of the pulmonary artery in transposition of the great vessels. Circulation, 33, 242.

Rao, P. S., and Sissman, N. J. (1971). The relationship of pulmonary venous wedge to pulmonary arterial pressures. Circulation, 44, 565.

Weissel, W., Salzmann, F., and Vetter, H. (1952). Pulmonary capillary arterial pressure pulse in man. British Heart fournal, 14, 47.

Wiener, F., Morkin, E., Skalak, R., and Fishman, A. P. (1966). Wave propagation in the pulmonary circulation. Circulation Research, 19, 834.

Wilson, R. H., Hoseth, W., and Dempsey, M. (1955). The inter-relations of the pulmonary arterial and venous wedge pressures. Circulation Research, 3, 3.

Wilson, R. H., McKenna, W. T., Johnson, F. E., Jensen, N. K., Mazzitello, W. F., and Dempsey, M. E. (1953). Significance of the pulmonary arterial wedge pressure. Fournal of Laboratory and Clinical Medicine, 42, 408.

Zimmerman, H. A. (1966). Intravascular Catheterization, 2nd ed. Charles C. Thomas, Springfield, Illinois.

Requests for reprints to Dr. John M. Celermajer, Adolph Basser Institute of Cardiology, Royal Alexandra Hospital for Children, Pyrmont Bridge Road, Camperdown 2050, Sydney, New South Wales, Australia. 